\title{
Primary Cutaneous Gamma-Delta T-Cell Lymphoma
}

National Cancer Institute

\section{Source}

National Cancer Institute. Primary Cutaneous Gamma-Delta T-Cell Lymphoma. NCI

Thesaurus. Code C45340.

An aggressive cutaneous lymphoma of mature, activated gamma/delta T-lymphocytes.

It usually presents with disseminated plaques and nodules. Involvement of mucosal sites

is frequent. However, involvement of lymph nodes, spleen, or bone marrow is

uncommon. Morphologically, there are three patterns of cutaneous involvement:

epidermotropic, dermal, and subcutaneous. Often, more than one pattern may co-exist in a single biopsy specimen, or may be present in different biopsy specimens from the same patient. The lymphocytic infiltrate is composed of medium- to large-sized lymphocytes expressing CD56. Most cases lack both CD4 and CD8, although CD8 may be present in some cases. This group of lymphomas includes cases previously known as subcutaneous panniculitis-like T-cell lymphoma with a gamma/delta phenotype. 